\title{
Hundred Million Cells
}

National Cancer Institute

\section{Source}

National Cancer Institute. Hundred Million Cells. NCI Thesaurus. Code C67248.

A unit of cell count expressed in hundreds of millions. 